\title{
NEUROFIBROMATOSIS TYPE I (VON RECKLINGHAUSEN DISEASE): A CASE REPORT AND REVIEW OF THE LITERATURE
}

\author{
J. Pozharashka¹, L. Dourmishev¹, E. Bardarov², M. Balabanova1', L. Miteva1 \\ ${ }^{1}$ Department of Dermatology and Venereology, Medical University - Sofia, Bulgaria \\ ${ }^{2}$ Hospital Europe, Europe Aesthetic Centre - Sofia, Bulgaria
}

\begin{abstract}
Neurofibromatosis type I is an autosomal dominant genetic disorder with an incidence of about 1 in 3000 births. Apart from the typical skin involvement NF1 may affect multiple organs with ocular, neurological, skeletal and cardiovascular manifestations. We present a case of a 38-year-old man with multiple café-au-lait macules and hundreds of neurofibromas disseminated on the trunk and extremities dating from childhood. To establish the diagnosis and to exclude any complications we performed multiple examinations, including skin biopsy, laboratory investigations, ophthalmologic assessment, consultations with a neurologist, internist and orthopedist, etc. The treatment of cutaneous NF1 is mainly symptomatic. Surgical excision aims to achieve cosmetic results. Recently novel and perspective conservative therapies have been investigated. In order to ensure better outcome for the patients with NF1 long-term multi-disciplinary approach is advised.
\end{abstract}

Key words: neurofibromatosis type I, cutaneous manifestations, treatment modalities

Corresponding author: Lyubomir Dourmishev MD, PhD, Department of Dermatology and Venereology, Medical University - Sofia, 1, Sv. Georgi Sofiyski Street, 1431 Sofia, Bulgaria, tel: +359 2 9230438, e-mail: I_dourmishev@mail.bg

\section{INTRODUCTION}

$\mathrm{N}$ eurofibromatosis type I (von Recklinghausen disease) is an autosomal dominant genetic disorder with an incidence of about 1 in 3000 births, due to gene mutation [1]. The NF1 gene is located on chromosome $17 \mathrm{q} 11.2$ and encodes the tumor suppressor protein neurofibromin, functioning as a Ras-GTPase-activating protein (RasGAP). Mutations of NF1 gene lead to loss of inhibitory function, overactivation of the Ras signaling pathway, uncontrolled cell proliferation and as an endpoint increased risk of developing benign and malignant tumors in affected individuals. For this reason, NF1 is considered tumor predisposition syndrome. Com- pared to the general population, NF1 patients have a fivefold risk for cancer and a more than 2000 -fold risk for neurogenic malignancies [1].

Apart from the typical skin involvement NF1 may affect multiple systems with ocular, neurologic, skeletal and cardiovascular manifestations. To establish the diagnosis of NF1, NIH Consensus Conference elaborated the following diagnostic criteria: (1) six or more café-au-lait macules over $5 \mathrm{~mm}$ in pre-pubertal individuals and over $15 \mathrm{~mm}$ in post-pubertal individuals; (2) two or more neurofibromas (cutaneous, subcutaneous) or one plexiform neurofibroma; (3), "freckling" in the axillary or inguinal region; (4) optic glioma; (5) two or more Lisch nodules; (6) osseous lesions (sphenoid dysplasia, pseudarthrosis); 
(7) first-degree relative with NF1 [2]. At least two of the seven criteria are required for a diagnosis of von Recklinghausen disease.

\section{CASE REPORT}

We present a 38-year-old man with multiple caféau-lait macules and hundreds of neurofibromas disseminated on the trunk and extremities dating from childhood (Fig. 1 A-C). Intertriginous, "freckling" was not observed on physical examination. The patient had no family history of neurofibromatosis, he was otherwise healthy and denied the presence of any systemic symptoms.

Multiple examinations were performed including biopsy of skin lesion, ophthalmologic assessment, consultations with a neurologist, internist and orthopedist. The patient refused molecular genetic testing.

Histopathology revealed circumscribed proliferation of spindle cells in superficial and mid-dermis. Numerous mast cells were visible in the tumor stroma (Fig. 2A). On higher magnification - tumor cells with elongated wavy monomorphous dark nuclei were present in the absence of nuclear pleomorphism or mitoses (Fig. 2B). Histopathology was consistent with a neurofibroma.

Routine laboratory investigations were within referent ranges. Ophthalmologic assessment revealed normal findings with preserved visual acuity. Lisch nodules were not detected. Consultations with a neurologist, internist and orthopedist were conducted, excluding any pathologic changes. MRI of the brain and spinal cord was recommended.

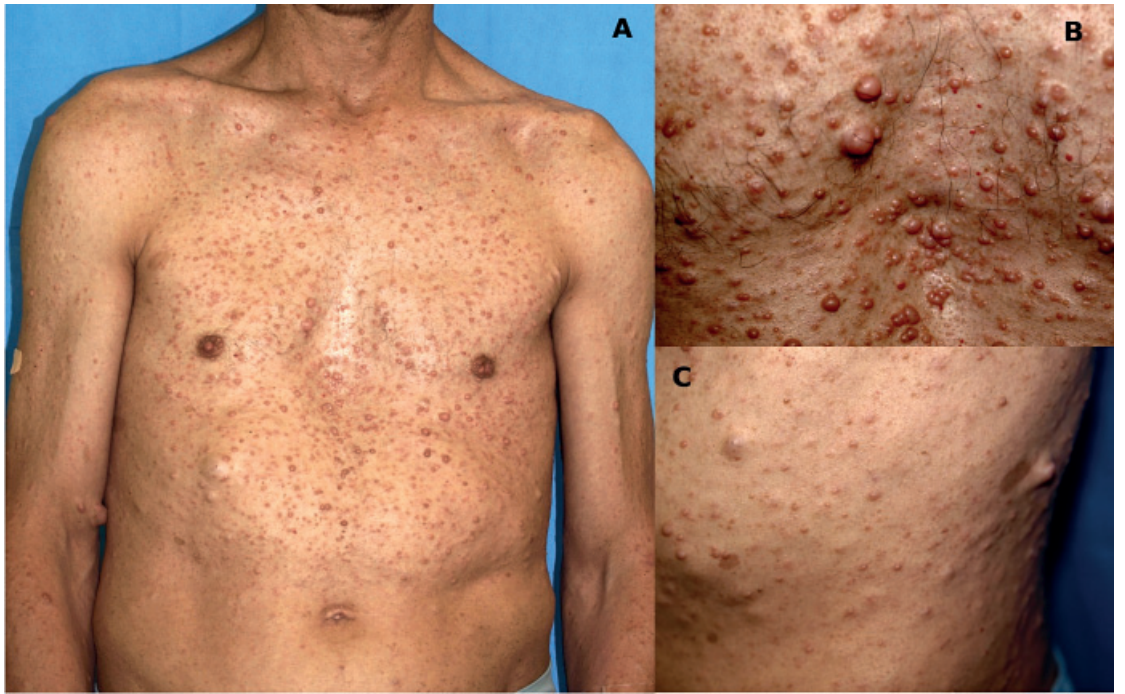

Fig. 1. A, B. Hundreds of neurofibromas disseminated on the trunk and extremities. C. Café-au-lait macules

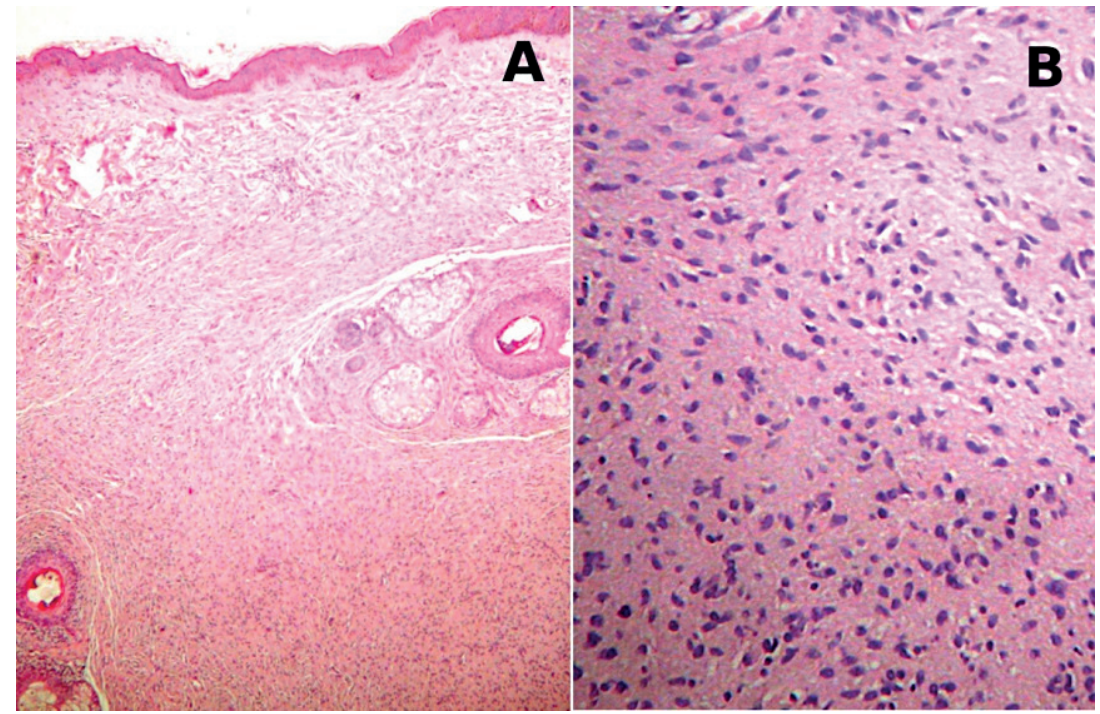

Fig. 2. A. Circumscribed proliferation of spindle cells in the dermis (H\&E x 100); B. Fragment of biopsy with tumor cells with elongated monomorphous dark nuclei (H\&E x 400) 


\section{DISCUSSION}

The neurofibromatosis type I was described in details by the pathologist Friederich Daniel von Recklinghausen in 1882 [3] and since then mainly case repots are published. In our case a definite diagnosis of neurofibromatosis type I can be made based on two positive diagnostic criteria fulfilled, namely the presence of six or more café-au-lait macules over $15 \mathrm{~mm}$ and two or more cutaneous neurofibromas. A molecular genetic analysis is not needed for diagnostic purpose. Testing of the NF1 gene is indicated for individuals in whom NF1 is suspected but who do not fulfill the NIH diagnostic criteria. This is rarely necessary after early childhood. Testing of an adult with NF1 is necessary if a pregnancy is expected [4].

The most important part of the care for adults with NF1 consists of regular follow-up aiming at early detection of systemic complications. This includes tumors (malignant peripheral nerve sheath tumors, optic glioma [5], other central nervous system tumors, pheochromocytoma [6], rhabdomyosarcoma, gastrointestinal stromal tumors, duodenal carcinoid, etc.), ocular abnormalities (Lisch nodules, glaucoma etc.), cardiovascular (hypertension - mostly essential, some from renal artery stenosis or pheochromocytoma), neurologic (seizures, cerebrovascular anomalies, etc.) or skeletal involvement. United Kingdom Neurofibromatosis Association Clinical Advisory Board's recommendation for asymptomatic adults comprises a minimum of annual blood pressure measurement and patient education concerning the clinical manifestations of malignant peripheral nerve sheath tumors and spinal cord compression. The patient should be instructed to immediately consult a specialist in case of persistent pain, loss of sensory or motor function and sphincter disturbances. Malignant peripheral nerve sheath tumors represent the primary concern in young adults. They usually arise in pre-existing plexiform neurofibromas, metastasize rapidly and are related to poor prognosis [4].

If the patient suffers from learning difficulties and mental retardation, he could benefit from social assistance or psychological help. To ensure such a wide spectrum approach and better outcome for the patients with NF1, usually a multi-disciplinary team is needed.

Our patient refused treatment for the cutaneous neurofibromas as he already got used to his physical appearance. The treatment of NF1 is mainly symptomatic. Surgical excision and laser ablation of neurofibromatous tissue aim to improve the complications or to achieve cosmetic results. Café-au-lait macules do not need or respond well to treatment and tend to recur after laser therapy.

Novel and perspective conservative therapies for cutaneous NF are in process of investigation due to the constant advancement in understanding pathophysiology of NF on genomic level. Such presumed therapeutic targets, undergoing clinical trial are mTOR, MEK and c-KIT [7]. Neurofibromatosis Clinical Trial Consortium (NFCTC) established in 2006 has conducted several studies for children and adults with neurofibromatosis type 1 and plexiform neurofibromas, neurocognitive challenges, low-grade gliomas, and malignant peripheral nerve sheath tumors [8-10]. The NF1 gene has also a major but yet not clearly understood role in cancerogenesis in sporadic tumors and further investigations are needed in this direction [11].

In conclusion, future validation of biomarkers for neurofibromatosis would be of great importance since the present ones are only exploratory. Such biomarkers are melanoma inhibitory activity (MIA), adrenomedullin (ADM), fetal antigen 1, soluble growth factor receptor $A x I$, aurora kinase $A$ etc. Some of them possess diagnostic, others - predictive value [12]. Finally, the advances in molecular genetics will promote the novel individual therapeutic strategies in genetic disorders.

\section{Acknowledgements}

Declaration of patient consent: The patient has given his consent for the clinical images and information concerning his disease to be reported in the journal, without mentioning his name, initials and other personal information.

\section{Conflicts of interest: None}

\section{REFERENCES}

1. Peltonen $S$, Kallionpää RA, Peltonen J. Neurofibromatosis type 1 (NF1) gene: Beyond café au lait spots and dermal neurofibromas. Exp Dermatol 2017;26(7):645-648.

2. Boyd KP, Korf BR, Theos A. Neurofibromatosis type 1. J Am Acad Dermatol 2009; 61(1): 1-16.

3. von Recklinghausen FD. Über die multiplen Fibrome der Haut und ihre Beziehung zu den multiplen Neuromen. Festschrift für Rudolf Virchow. Berlin, 1882.

4. Ferner RE, Huson SM, Thomas N, et al. Guidelines for the diagnosis and management of individuals with neurofibromatosis 1. J Med Genet 2007;44(2):81-8. 
5. Surchev JK, Nachev S, Todorova LP, et al. Optic Nerve Glioma in Two Sisters with Family History of Neurofibromatosis Type 1. J Neurol Surg A Cent Eur Neurosurg. 2018;79(3):268-272.

6. Vlenterie M, Flucke U, Hofbauer LC, et al. Pheochromocytoma and gastrointestinal stromal tumors in patients with neurofibromatosis type I. Am J Med. 2013;126(2):174-80.

7. Allaway RJ, Gosline SJ, La Rosa S, et al. Cutaneous neurofibromas in the genomics era: current understanding and open questions. Br J Cancer 2018;118(12):1539-1548.

8. Packer RJ, Fisher MJ, Cutter G, et al. Neurofibromatosis Clinical Trial Consortium. J Child Neurol 2018;33(1):82-91.

9. Widemann BC, Acosta MT, Ammoun S, et al. CTF meeting 2012: Translation of the basic understanding of the biology and genetics of NF1, NF2, and schwannomatosis toward the development of effective therapies. Am J Med Genet A 2014; 164(3):563-78.

10. Walker JA, Upadhyaya M. Emerging therapeutic targets for neurofibromatosis type 1. Expert Opin Ther Targets 2018;22(5):419-437.

11. Rad E, Tee AR. Neurofibromatosis type 1: Fundamental insights into cell signalling and cancer. Semin Cell Dev Biol 2016; 52:39-46.

12. Hanemann CO, Blakeley JO, Nunes FP, et al. Current status and recommendations for biomarkers and biobanking in neurofibromatosis. Neurology 2016;87(7 Suppl 1): S40-8.

Received August, 2019 - Accepted August, 2019 